\title{
APOROFOBIA: (IN)VISIBILIDADE E (IN) ACEITABILIDADE? UMA ABORDAGEM NECESSÁRIA A PARTIR DA COMPREENSÃO E DOS MEIOS PROFÍCUOS CAPAZES DE ATENUAREM OS EFEITOS DENTRO DA SOCIEDADE MULTIFACETADA
}

Aporophobia: (in)visibility and (in)acceptability? A necessary approach from understanding and fruitful means able to mitigate the effects within the multifaceted society

\author{
Simone Paula Vesoloski ${ }^{1}$
}

${ }^{1}$ Mestranda Bolsista PROSUP/CAPES do Programa de Pós Graduação em Direito - Faculdade Meridional, IMED; Pós Graduanda em Direito do Trabalho e Processo do Trabalho com ênfase na Reforma Trabalhista - Grupo Verbo; Graduada em Direito - Universidade Regional Integrada do Alto Uruguai e das Missões; membro do Centro Brasileiro de Pesquisas sobre a Teoria da Justiça de Amartya Sen da IMED - Passo Fundo e do Grupo de Pesquisa Trabalho e Capital: Retrocesso Social e Avanços Possíveis da Universidade Federal do Rio Grande do Sul.E-mail: simonels17@hotmail.com

Data do recebimento: 27/01/2021 - Data do aceite: 20/04/2021

RESUMO: A palavra aporofobia surge para intitular o desprezo ao pobre. É relevante compreender como a aporofobia se contextualiza na sociedade. $\mathrm{O}$ objetivo desse estudo analisou o que é aporofobia. Buscou-se verificar quais os meios capazes de erradicar a pobreza, investigando os desafios. A metodologia utilizada compreende o raciocínio indutivo, analítico-descritivo, com técnica de pesquisa bibliográfica. O pobre tende a ser excluído e desprezado essa aversão afronta sua dignidade. Acredita-se que a partir do reconhecimento da aporofobia, efetividade nas ações mitigadoras e, por meio da educação, será possível gerar uma mudança satisfatória, tornando o mundo mais humanizado e solidário com o outro.

Palavras-chave: Aporofobia. Aversão. Desprezado. Excluído. Pobreza. 
ABSTRACT: The word aporophobia comes to mean contempt for the poor. It is relevant to understand how aporophobia is contextualized in society. This study analyzed what aporophobia is. We sought to verify which means are capable of eradicating poverty, investigating the challenges. The methodology used comprises inductive, analytical-descriptive reasoning, with bibliographic research technique. The poor tend to be excluded and despised, this aversion affronts their dignity. It is believed that from the recognition of aporophobia, effectiveness in mitigating actions and through education, it will be possible to generate a satisfactory change, making the world more humanized and solidary with the other.

Keywords: Aporophobia. Aversion. Scorned. Excluded. Poverty.

\section{Introdução}

Em meio à sociedade contemporânea e plural, o ser humano com menos condições, menor viabilidade de vida em comparação com a classe média e alta é visto, na maioria dos casos, como um 'problema', taxado como inferiorizado, sendo ignorado e desprezado. Essa conduta está enraizada e gera efeitos negativos, ofende a moral e a dignidade das pessoas afetadas com essas atitudes destrutivas e discriminatórias. De modo generalizado e amplo, esse desprezo, essa 'invisibilidade', essa discriminação, seja com o pobre, com o negro, o homossexual, com o bissexual, com as pessoas com limites e/ou má formação física, prostitutas, mulheres, enfim, atingem uma grande parcela da população que vive a mercê dessas condutas e práticas corrosivas e maléficas.

Desse modo, o conteúdo para embasar esta pesquisa ocorreu em artigos, sites relacionados ao tema, livros e a legislação associada ao tema abordado. A metodologia de análise é a indutiva e o método analítico-descritivo. A problemática em tela é: o que se entende por aporofobia e se ela é (in) visível, (in)aceitável e compreensível para a sociedade? Este estudo pretende esclarecer e compreender a aporofobia, termo nominado pela autora Adela Cortina quando se refere à aversão que a sociedade tem em relação ao pobre. Assim, a abordagem dessa pesquisa engloba essa nova nominação que atinge corrosiva e destrutivamente a sociedade contemporânea.

Ainda, perscrutou-se investigar quais os meios profícuos e as alternativas adotadas para erradicar a pobreza e como consequência, reduzir a aporofobia, bem como, buscou-se analisar e retratar quais os desafios e as estratégias utilizadas para minimizar os efeitos da aporofobia e como é possível empoderar os mais vulneráveis, ou seja, os mais pobres.

Cultivar e manter condutas que estimulam o desprezo com o outro são condutas que devem, imprescindivelmente, serem banidas dentro da sociedade plural e contemporânea. Essa aversão, repulsa, nojo e desprezo para com o pobre e, outras formas de discriminação, preconceito e racismo causam uma ofensa imensurável para a vítima, além de causar angústia, dor, isolamento, que muitas vezes repercutem para um quadro de depressão, de ansiedade, fobias e uma séries de outros efeitos negativos, e, que em casos extremos, podem, sim, levar ao suicídio. A aporofobia não é recente, merece ser discutida, pois se 
trata de um grande problema, que muitas vezes a sociedade não quer enxergar e até nem sabe como lidar. Além do mais, a aporofobia perpassa de uma geração para outra, se tornando recorrente e 'normal', contudo, é crucial e extremamente importante reconhecer tal conduta e concretizar uma mudança, banindo e extirpando a aporofobia da sociedade atual.

\section{Aporofobia: compreendendo a conceituação}

A palavra aporofobia foi nominada pela escritora, professora universitária de Filosofia Moral e Política da Universidade de Valência, diretora acadêmica da Fundação ÉTNOR (Ética de los negocios y las organizaciones), primeira mulher a ingressar como membra plena da Academia Real de Ciências Morais e Políticas da Espanha, doutora honoris causa por diversas universidades europeias e latino-americanas: Adela Cortina, no qual ela buscava dar um nome a essa patologia social e para poder diagnosticá-la com mais precisão, para então descobrir sua etiologia e propor meios de tratamentos efetivos. Desse modo, encontrou no vocabulário grego um termo pra designar o pobre, o sem recurso, e nessa busca encontrou o vocábulo áporos, que permitiu construir o termo aporofobia, por analogia com xenofobia, homofobia e outras palavras com o sufixo 'fobia'.

Segundo Cortina (2020, p. 19), a aporofobia é compreendida como

o desprezo pelo pobre, o rechaço a quem não pode entregar nada em troca, ou, menos, parece não poder. E por isso é excluído de um mundo construído sobre o contrato político, econômico ou social desse mundo de dar e receber, no qual só podem entrar os que parecem ter algo de interessante para dar em retorno.
Nesse sentido, a autora supramencionada aduz que a maioria das pessoas compreende que o pobre traz mais problemas dentro da sociedade, e a partir dessa concepção, a tendência natural de uma parte da sociedade é excluí-los. Ainda, a autora destaca que o surgimento da aporofobia está entrelaçado como um atentado diário e invisível contra a dignidade, contra o bem-estar social e o bem-estar do ser humano a que se refere; e quem despreza assume uma atitude de superioridade em relação ao outro.

Este é o ponto central no mundo das fobias grupais: a convicção de que existe uma relação de assimetria, de que a raça, a etnia, a orientação sexual, a crença religiosa ou ateia de quem despreza sejam superiores às de quem é o objeto da rejeição. Por isso, o indivíduo se considera legitimado para atacar as atitudes e as palavras, as quais, no fim das contas, também são uma maneira de agir. (CORTINA, 2020, p. 23).

De acordo com Silva (2020), a pobreza e a miserabilidade são problemas pungentes, e claramente estão consolidados na formação do povo brasileiro. Toda a diferenciação entre rico e pobre e a desigualdade no tratamento é perceptível, e piora de modo crescente no contexto atual da pandemia que assola o país, onde a economia global oscila a todo instante e os reflexos, de tudo isso, recai sobre a população que menos tem.

Ser pobre gera um fardo pesado nas 'costas' das pessoas pertencentes a esta classe social. Além da dificuldade rotineira são submetidos a taxações, pré-conceitos, exclusões, diminuição do poder de escolha, limitação na liberdade, nas oportunidades, entre outros fatores que impedem o fluxo de vida de uma pessoa com melhores condições.

Destarte, para Silva (2020) a pobreza personifica a supressão, a negação e a violação dos direitos humanos fundamentais e sociais. Ela retira do ser humano a possibilidade de 
usufruir e de ter acesso a bens materiais e imateriais, obsta a plenitude de sua liberdade e coloca esta pessoa na condição de desalento.

Nesse diapasão, Araújo (2020), define o termo aporofobia como uma palavra que foi recentemente incorporada ao léxico da língua espanhola e expressa um enorme e indisfarçável ódio, intangível, mas real, voltado aos pobres ou às classes sociais que se encontram na base da pirâmide social, retratando e se voltando a estas pessoas com desprezo, repulsa, aversão ou nojo.

É importante ressaltar, segundo Cortina (2020), que este preconceito ao pobre não ocorre somente por classes médias e altas para as baixas. Essa aporofobia ocorre inclusive em família, com pessoas conhecidas, pois muitos consideram que ter parente pobre é vergonha que deve ser escondida, então convém deixá-los de lado. É essa fobia do pobre que leva à rejeição às pessoas que não tem recursos.

Para a autora supramencionada, intitular aporofobia para essa aversão, essa característica que inscreve um determinado grupo de pessoas que se despreza ou se teme, é um caminho para o reconhecimento das causas e para impulsionar a busca de caminhos viáveis para superar esses desafios do nosso tempo. Além do mais, é importante deixar claro que a pobreza não é apenas a carência dos meios necessários para sobreviver. Tem muitas coisas que evidenciam a noção de pobreza.

Nesse contraponto, em relação à pobreza, ela é caracterizada pela falta de meios necessários para sobreviver com qualidade e com dignidade, como por exemplo, falta de alimentação, de vestuário, moradia, cuidados com a saúde, podendo ser caracterizada também pela falta de bens e serviços essenciais, falta de recursos financeiros, ainda podem ser entendida como carência social associada à própria exclusão social e a incapacidade de participar da sociedade (falha no sistema de abrangência democrática). Sendo assim, na próxima seção serão apresentados quais os meios eficazes e realmente efetivos para erradicar a pobreza e reduzir a aporofobia.

\section{Meios profícuos e alternativas voltadas para a erradicação da pobreza e como consequência, redução da aporofobia}

Para tentar diminuir as consequências da aporofobia, Adela Cortina (2020, p. 50) aduz que é

preciso descobrir as raízes profundas da aporofobia, tratar de investigar suas causas, averiguar se formam parte da natureza humana, de modo que os pobres sempre serão desprezados e, na realidade, é impossível mudar a atitude de rejeição perante eles. Ou então, descobrir se existem caminhos pelos quais cada pessoa e cada sociedade possam mudar por entender e sentir que essa atitude é contraria à humanidade mais elementar. Esse é o desafio que enfrenta a educação moral, que deve vir acompanhada de instituições políticas e econômicas encaminhadas na mesma direção, porque não apenas as escolas, as universidades e as famílias educam, mas também as instituições econômicas e políticas e os meios de comunicação.

Como todas as fobias são consideradas crime, exemplificando a xenofobia (que se trata do medo, da aversão ou profunda antipatia em relação aos estrangeiros), o racismo, o preconceito, a discriminação, a homofobia (se refere ao medo do igual ou pavor do parecido, como a rejeição à homossexualidade, que é uma orientação sexual), a aporofobia também pode ser considerada crime.

Nesta senda, é relevante esclarecer que Bezerra (entre 2017 e 2020) considera o pre- 
conceito como uma opinião prévia formada, um julgamento superficial e, geralmente negativo, sobre um indivíduo ou um grupo de pessoas, sem conhecê-los. Já o racismo se pauta na perspectiva de que existem raças superiores e outras inferiores. E por fim, a discriminação é o ato, a ação que se fundamenta no preconceito ou no racismo, onde um indivíduo trata o outro de modo desrespeitoso, inferior ou injusto, pelo simples fato de se achar superior ou melhor.

O Art. $1^{\circ}$ da Declaração Universal dos Direitos Humanos prevê que "todos os seres humanos nascem livres e iguais em dignidade e em direitos. Dotados de razão e de consciência, devem agir uns para com os outros em espírito de fraternidade", por esta razão devem ser tratados de igual modo, se distinção. Ademais, ainda o Art. $7^{\circ}$ da mencionada Declaração preceitua que "todos são iguais perante a lei e, sem distinção, têm direito a igual proteção da lei. Todos têm direito à proteção igual contra qualquer discriminação que viole a presente Declaração e contra qualquer incitamento a tal discriminação".

Como seria de praxe, todos deveriam ser tratados com respeito, com alteridade, como gostariam que fossem tratados, mas sabe-se que na sociedade contemporânea a realidade se demonstra de modo contrário com o esperado, com o almejado e traçado na própria lei nacional e internacional.

Nesse compasso, Cortina (2020) sintetiza que não é possível exigir dos cidadãos que tomem os princípios do Direito como parâmetro de suas ações, mas é imprescindível que não violem esses princípios. Eliminar a aporofobia e outras fobias exige respeito mútuo à dignidade das pessoas.

\section{Adela Cortina aduz que a}

aporofobia tem bases cerebrais e sociais, que, felizmente, podem ser modificadas, e os caminhos mais adequados para essa transformação são a educação, enten- dida em sentido amplo, e a construção de instituições econômicas, políticas e sociais capazes de promover o respeito à igual dignidade de cada uma das pessoas concretas. Porém, os dois caminhos seriam intransitáveis se não existisse nas pessoas o que se chama tradicionalmente de "consciência moral", capaz de assumir o controle da própria vida, capas de agir por si mesma e não apenas por pressão do entorno. (CORTINA, 2020, p. 97).

Desse modo, é imprescindível que a sociedade, como um todo, crie alternativas para rejeitar comportamentos e atitudes aporófobos e criem alternativas que empoderem e valorizem os pobres.

Em relação à valorização, inclusão do pobre e na tentativa de banir a aporofobia, Cortina (2020, p. 113) assevera que

seria conveniente divulgar que valorizamos as ações que tendem a incluir ao invés de excluir, ações que se preocupam em acolher e não em rejeitar aqueles que parecem não ter nada a retribuir; seria conveniente divulgar ainda que, em nossas sociedades, concordamos com Adam Smith sobre o desprezo que deve ser dirigido ao vício e à estupidez, mas não à pobreza. Esse é um conselho que, em minha opinião, não deve ser descartado no mundo educacional, empresarial, ou político.

Assim, a autora supramencionada destaca que é preciso educar as pessoas, começando pelas crianças, educar para a autonomia, para gerar uma consciência tecida por meio do diálogo e da argumentação, não se deixando levar e enganar pela força da pressão social. A sociedade precisa compreender que ela vive entrelaçada um com o outro, não existe indivíduo isolado, existem vidas humanas em vínculos a todo instante. A educação está associada com a erradicação e superação de todas as patologias sociais e que terminam com o sufixo fobia. 
Portanto, o pior castigo que pode ser dado é a condenação à invisibilidade, ao desconhecimento da existência do outro, à rejeição e ao desprezo. É o reconhecimento mútuo o que basicamente nos constitui como seres humanos, o que faz com que possamos levar nossas vidas adiante a partir do reconhecimento compassivo que assenta os cimentos de uma sociedade inclusiva. Descobrir esse vínculo, essa ligatio de pertencimento mútuo, faz surgir obrigações como as que nascem do respeito à dignidade do outro, o amplo campo da justiça, mas que ainda vão mais longe, porque abrem o mundo caloroso da gratuidade. (CORTINA, 2020, p. 118-119).

Apesar de a educação ter um papel muito importante na construção de uma sociedade mais humanizada, ela não é a única a desempenhar a função da mudança esperada. Para Cortina (2020) a educação, cumulada com a argumentação e o raciocínio são de extrema valia, mas ainda são insuficientes, é necessário modificar também as emoções, ligadas à motivação.

Ademais, Cortina (2020, p. 138) salienta que o conjunto de emoções humanas deve estar alinhado à sensibilidade, por exemplo, deve ser manifestada "a irritação quando alguém causa dano à outra pessoa; o desejo de represália que dissuade futuras agressões, o remorso e sentimento de culpa; a vergonha”, a capacidade de perdoar. Todo esse aparato moral deve ser complementado com a educação.

Assim, Cortina (2020) retrata que os pobres, na maioria das vezes, não são totalmente invisíveis, eles são inviabilizados, vistos por uma parcela da população como problema. Desse modo, a autora acredita que a mudança deve ocorrer com a mudança de pensamento, pois o cérebro humano é aporófobo, grande parte das pessoas nascem com a tendência de ignorar quem não traz ou oferece benefícios, e a real mudança de comportamento deve ocorrer ao longo da vida de cada ser humano.

Para produzir essa mudança na direção de ideais igualitários é necessário contar com a educação na família, na escola, na mídia e no conjunto da vida pública. Mas também é necessário construir os tipos de instituições e organizações que caminham nessa direção, porque não serão apenas justas, que é o que lhes corresponde, mas ajudarão a configurar pessoas com caráteres justos. As instituições e organizações realizam tarefas mais ou menos acertadas, mas ao mesmo tempo em que educam com a sua mera existência e atuação, influenciam na conformação do cérebro e do caráter pessoal e social. (CORTINA, 2020, p. 148).

Nesse compasso, Cortina (2020) salienta que o compromisso de erradicar a pobreza tem sido uma escolha de certos indivíduos, grupos, associações ou instituições voluntárias. Contudo, essa colaboração é importante, mas não deveria ser a única, erradicar a pobreza deve ser vista como um dever de justiça a serem cumpridos pelos poderes políticos.

Nessa linha, a pobreza em si gera falta de oportunidade, de liberdade. Assim, Amartya Sen (2000) menciona que as liberdades que o ser humano tem é o fruto do desenvolvimento, caracterizadas pela "oportunidade econômica, liberdade política, poderes sociais, e por condições de boa saúde, educação básica" (SEN, 2000, p. 19). Contudo, ele ressalta que o desenvolvimento requer a remoção das privações de liberdade.

Desse modo, Sen (2000) elenca e vincula as principais fontes de privação de liberdade:

[...] pobreza e tirania, carência de oportunidades econômicas e destituição social sistemática, negligência dos serviços públicos e intolerância ou interferência excessiva de Estados repressivos. A despeito de aumentos sem precedentes na opulência global, o mundo nega liberdades elementares a um grande número de pessoas, talvez 
até mesmo à maioria. Às vezes a ausência de liberdades substantivas relaciona-se diretamente com a pobreza econômica, que rouba das pessoas a liberdade de saciar a fome, de obter uma nutrição satisfatória ou remédios para doenças tratáveis, a oportunidade de vestir-se ou morar de modo apropriado, de ter acesso a água tratada e saneamento básico. Em outros casos, a privação de liberdade vincula-se estreitamente à carência de serviços públicos e assistência social, como por exemplo, a ausência de programas epidemiológicos, de um sistema bem planejado de assistência médica e educação ou de instituições eficazes para a manutenção da paz e da ordem local. Em outros casos, a violação da liberdade resulta diretamente de uma negação de liberdades políticas e civis por regimes autoritários e de restrições impostas à liberdade de participar da vida social, política e econômica da comunidade. (SEN, 2000, p. 18).

Dessa maneira, Sen (2000) frisa que as privações de liberdades podem ser minimizadas com, "alguém que age e ocasiona mudança e cujas realizações podem ser julgadas de acordo com seus próprios valores e objetivas" (SEN, 2000, p. 33). Esse alguém é denominado, na sua linha de raciocínio, como agente na condição de membro do público e como participante das ações econômicas, sociais e políticas.

Cortina (2020) ressalta que erradicar a pobreza é um dever da humanidade, da consciência social, a fim de erradicá-la. Dia após dia ganha novos olhos, se amplia em escala global e o ativismo internacional está ganhando mais visibilidade e aumentando. Porém, tudo ainda é recente, mas é um passo sem volta.

A partir do momento que houver sensibilização, conscientização, a mudança começará a engatinhar para produzir efeitos maiores e mais benéficos para a sociedade. A próxima seção se preocupa em explicitar e apontar quais os desafios e as estratégias que estão sendo utilizadas para mitigar os efeitos da aporofobia e para empoderar os menos favorecidos.

\section{Desafios e estratégias para minimizar os efeitos da aporofobia e empoderar os mais vulneráveis}

\author{
Cortina (2020, p. 167) retrata que para
}

\begin{abstract}
empoderar os pobres é necessário, entre outras coisas, superar fatores externos, como a incompletude dos mercados, os governos incorretos ou o acesso desigual aos inputs produtivos ou financeiros. Nesse sentido, foi corretamente que um dos desafios, senão o maior, consiste em reduzir as desigualdades, porque são indesejáveis em si mesmas e pela pobreza que geram.
\end{abstract}

Assim, para a autora supramencionada, reduzir as desigualdades, por meio de medidas que propiciem o desenvolvimento com as pessoas afetadas pela pobreza é uma forma benéfica de se agir com eficácia e com justiça. Desse modo, "criar instituições que eliminem a pobreza e reduzam as desigualdades é a melhor maneira de a economia ajudar a erradicar a aporofobia". (CORTINA, 2020, p. 169).

Segundo Sen (2011), minimizar a pobreza está associado com o desenvolvimento. Quanto mais desenvolvimento o país tiver, maior será a liberdade do indivíduo. Desse modo, o autor destaca que o desenvolvimento e a democracia devem "ser vistas, em parte, com relação à sua ligação constitutiva, e não apenas através de ligações externas", (SEN, 2011, p. 381). Em razão disso, Sen (2011) salienta que a liberdade política e os direitos democráticos são componentes dessa ligação constitutiva de desenvolvimento. 
Sendo assim, o desenvolvimento amplia a liberdade, por conseguinte, a capacidade de cada indivíduo e, obviamente, reduz a pobreza e a aporofobia em si. Deste modo, Sen (2000) parte da premissa que deve ser observada a relação entre a liberdade política, que tem o papel de fornecer informações na solução de necessidades econômicas e compreender a real satisfação dessas necessidades, sendo que essa percepção depende de discussão e debate público aberto, para garantir a liberdade política e direitos civis básicos, pois é a partir deles que é possível demonstrar:

1) sua importância direta para a vida humana associada a capacidades básicas (como a capacidade de participação política e social);

2) seu papel instrumental de aumentar o grau em que as pessoas são ouvidas quando expressam e defendem suas reivindicações de atenção política (como as reivindicações de necessidade econômica);

3) seu papel construtivo na conceituação de 'necessidades ' (como a compreensão das 'necessidades econômicas' em um contexto social). (SEN, 2000, p. 175).

Nesse aspecto, resta claro que o desenvolvimento é crucial para a sociedade, assim, a garantia de uma participação democrática efetiva garante o reconhecimento real das verdadeiras e emergentes necessidades dos seres humanos plurais, garantindo que todas as vozes sejam realmente ouvidas por meio do debate público.

Contudo, não basta criar espaços de escuta e conhecimento dos anseios da população é necessário efetivar a escuta e traduzir em resultados. Segundo Cortina (2020) é necessário o reconhecimento da dignidade alheia e própria, o respeito por quem tem dignidade e não um simples preço. Nesse contexto é importante levar em conta a solidariedade com os cidadãos que estão em situação de vulnerabilidade.

Nesse viés, Cortina (2020, p. 199) expõe que "uma educação à altura do século XXI tem a tarefa de formar pessoas de seu tempo, de seu lugar concreto e abertas ao mundo. Sensíveis aos grandes desafios [...]", desafios estes relacionados ao drama da pobreza extrema, da fome, da miserabilidade e da falta de defesa dos vulneráveis. "Educar para o nosso tempo exige formar cidadãos compassivos, capazes de assumir a perspectiva dos que sofre, mas, sobretudo, de se comprometerem com eles". (CORTINA, 2020, p. 199).

Levitsky e Ziblatt (2018) ressaltam que poucas sociedades conseguiram, até hoje, funcionar numa era de igualdade e diversidade. O maior desafio da atualidade se concentra nessa busca pela inclusão e não pela exclusão dos povos. Se mudarmos a postura, o mundo será melhor.

De acordo com Piketty (2020) ninguém deterá a verdade absoluta sobre o que realmente é uma sociedade justa, mas as sociedades humanas devem ser vistas como as detentoras da busca pela justiça, superando a herança desigualitária pesadíssima ligada a crenças e castas.

É importante ressaltar, de acordo com Cortina (2020), compreender que a partir do momento que for erradicado a pobreza, haverá uma redução significativa das desigualdades, mas para isso as pessoas deverão ter o senso de mudança, acentuando a sensibilidade social e cultivando o sentimento de igual dignidade.

A prática da aporofobia é inaceitável. É imprescindível que o ser humano transmute a realidade e realmente promova mudança, se (re)eduque e (re)crie um novo modo de lidar com o seu próximo, baseado na alteridade, na empatia, no respeito e acima de tudo na preservação e manutenção da dignidade e dos direitos. 


\section{Conclusão}

Como bem visto, a aporofobia causa uma série de malefícios não apenas para as vítimas que sofrem com esse desprezo, esta aversão, mas corrói a sociedade. Esse tipo de aversão jamais deveria ser motivo para um ser humano desprezar outro, para ensejar discriminação, críticas, rechaços ou qualquer conduta que atinja a moral e a dignidade de outrem.

Além da angústia, da baixa estima, dor, isolamento, ansiedade, problemas com depressão, vícios com drogas, a vítima da aporofobia, que muitas vezes é vinculada com outras formas de discriminação, pode apresentar problemas psicológicos e, em casos mais extremos, pode chegar a cometer o suicídio.

Erradicar a aporofobia não é algo impossível, porém desafiador. A educação se mostra uma grande aliada, juntamente com debates, estratégias, ações educacionais, políticas públicas, entre outras ferramentas capazes de proporcionar uma transformação na capacidade racional do ser humano e sensibilizar para que a mudança realmente aconteça. É imprescindível repensar a conduta humana, ter alteridade e empatia com o próximo, reavaliar o modo de agir, compreendendo que a aporofobia realmente afeta a dignidade, a moral, o bem estar-social...

Para muitas vidas desesperançadas, acredita-se que é por meio da educação e do debate aberto que será possível reduzir a vulnerabilidade e proporcionar um espaço de autonomia e horizontalidade de comunicação. Instrumentos eficazes e políticas públicas pra acelerar o desenvolvimento são necessários. Por conseguinte, com a melhora no desenvolvimento social, econômico e político, a capacidade e a oportunidade dos indivíduos são maximizadas, mudando o quadro de vulnerabilidade e dando espaço para minimizar a pobreza.

Toda a sociedade deve ter o compromisso efetivo com o propósito de modificar condutas que terminam com o sufixo 'fobia', em especial a aporofobia e, com isso, erradicando-as. Essa mudança almejada só é possível concretizar a partir do momento em que cada ser humano compreende a dimensão da prática e todos os impactos que rondam tal conduta. Com o reconhecimento, a sensibilização e vontade de instrumentalizar a mudança, será possível resgatar e dignificar a sociedade, permitindo a legitimação dos direitos humanos e dos direitos fundamentais, assegurando a proteção dos direitos inerentes ao ser humano, elevando-o a um patamar mais equânime, justo, democrático, humanizado, igualitário e com valores pautados no Direito, na justiça e no ser humano.

\section{REFERÊNCIAS}

ARAÚJO, C. E. Aporofobia: o ódio aos pobres em tempos sombrios. Disponível em: https://www. justificando.com/2020/02/19/aporofobia-o-odio-aos-pobres-em-tempos-sombrios/. Acesso em: 24 jan. 2021.

BEZERRA, J. Preconceito, racismo e discriminação. Disponível em: https://www.diferenca.com/ preconceito-racismo-e-discriminacao/. Acesso em: 16 jan. 2021. 
CORTINA. A. Aporofobia, a aversão ao pobre: um desafio para a democracia. Tradução de Daniel Fabre. São Paulo: Editora Contracorrente, 2020.

Declaração Universal dos Direitos Humanos. Disponível em: https://www.ohchr.org/EN/UDHR/ Pages/Language.aspx?LangID=por. Acesso em: 16 jan. 2021.

LEVITSKY, S.; ZIBLATT, D. Como as democracias morrem. Tradução Renato Aguiar. Rio de Janeiro: Zahar, 2018.

PIKETTY, T. Capital e Ideologia. Tradução Maria de Fátima Oliva do Coutto e Dorothée de Bruchard. Rio de Janeiro: Intrínseca, 2020.

SEN, A. A ideia de justiça. Tradução Denise Bottmann, Ricardo Doninelli Mendes. $5^{\circ}$ Reimpressão. São Paulo: Companhia de Letras, 2011.

SEN, A. O desenvolvimento como liberdade. Tradução Laura Teixeira Motta. São Paulo:

Companhia das Letras, 2000.

SILVA, D. R. Estado de mal estar social: a pobreza e aporofobia no Brasil. Disponível em: http:// conpedi.danilolr.info/publicacoes/olpbq8u9/4366w0w9/XUzdFRN0A15rhs18.pdf. Acesso em: 25 jan. 2021. 